\title{
Gene targeting at the human CD4 locus by epitope addition
}

\author{
Maria Jasin, Stephen J. Elledge, ${ }^{1}$ Ronald W. Davis, and Paul Berg \\ Department of Biochemistry, Beckman Center, Stanford University School of Medicine, Stanford, California 94305-5307 USA
}

\begin{abstract}
Homologous recombination at the CD4 locus in a human T-cell line has been achieved by an approach called epitope addition. The endogenous $C D 4$ gene provided transcription, translation, and leader sequences to a crippled introduced Thy-1 gene, resulting in the expression of murine Thy-1 epitopes on the surface of the human cells. Thy-1 ${ }^{+}$cells were selected using the Fluorescence Activated Cell Sorter (FACS). An estimated 700 -fold enrichment for homologous versus nonhomologous integration events was obtained, such that $70 \%$ of cells scoring positive for Thy-1 were derived from gene targeting. Three of the Thy-1+ cell lines expressed protein only from the targeted allele; thus, these cells were functionally $\mathrm{CD4}^{-}$.
\end{abstract}

[Key Words: Gene targeting; CD4; human T cells; epitope addition; Thy-1]

Received October 23, 1989; revised version accepted December 4, 1989.

Targeted recombination at selected chromosomal loci has been a powerful approach in the elucidation of gene function in lower eukaryotes. Similar studies in mammalian systems have been hampered by the preponderance of nonhomologous recombination between introduced DNAs and the genome. Recently, screening methods have been improved to allow the identification of the rare cells that have undergone specific recombinations (Kim and Smithies 1988; Joyner et al. 1989; Zimmer and Gruss 1989). In addition, selection protocols have been developed that enrich for the recovery of cells that have undergone homologous events (Doetschman et al. 1988; Jasin and Berg 1988; Mansour et al. 1988; Dorin et al. 1989; Sedivy and Sharp 1989).

Previously, we described a strategy to obtain an $\sim 100$ fold enrichment for homologous recombination events (Jasin and Berg 1988). Our approach relied on the ability of the SV40 early region in COS cells to provide transcription signals to activate a defective selectable marker, the gpt gene, upon homologous integration. Most random integrations of the defective gpt gene did not confer a selectable phenotype to the cells. We now present an approach in which the coding region of a target gene is specifically altered by the recombination event. The method relies on activating the expression of unique epitopes on the surface of cells that have undergone a homologous recombination event and the identification of these cells using antibody probes. The method is called epitope addition and has been applied to the $C D 4$ gene in a human $\mathrm{T}$-cell line.

The cell-surface glycoprotein CD4, which is expressed on a subset of T-cells and macrophages, is an important accessory molecule for antigen-dependent $T$-cell activa-

${ }^{1}$ Current address: Department of Biochemistry, Baylor College of Medicine, Houston, Texas 77030 USA. tion and serves as the receptor for the human immunodeficiency virus (HIV; Wilde et al. 1983; Dalgleish et al. 1984; Klatzman et al. 1984; Rogozinski et al. 1984). We constructed a fusion between $\mathrm{CD} 4$ and the murine T-cell marker Thy-1. To replace the chromosomal CD4 gene with the gene encoding this altered CD4, a targeting plasmid was constructed that contains a portion of the CD4/Thy-1 gene fusion but lacks a promoter, translation start, and signal sequence. This severely crippled gene was repaired by homologous integration at the CD4 locus, resulting in the expression of Thy-1 epitopes on the cell surface. This approach yielded an enrichment of several hundredfold for homologous versus nonhomologous recombination events: Greater than $70 \%$ of the selected clones arose from homologous integrations at the CD4 locus.

\section{Results}

Strategy for targeted recombination at the CD4 locus

Our aim is to use targeted recombination to construct a $C D 4 / T h y-1$ fusion gene that directs the cell-surface expression of a protein consisting of extracellular domains from CD4 linked to Thy-1 extracellular and membranebound domains. To distinguish homologous from nonhomologous integrants, the transfecting DNA contains a crippled fusion gene-one that lacks the promoter, translation start, and leader sequence. Homologous integration of a plasmid containing the incomplete fusion at the $C D 4$ locus should restore an intact fusion gene and give rise to Thy-1 epitopes on the cell surface. The strategy consists of electroporating plasmid DNA, which includes a linked gpt gene, into a human T-cell line that expresses high levels of CD4 on the cell surface, selecting $\mathrm{gpt}^{+}$transformants and screening for 
Thy- $1^{+}$cells by flow cytometry. To identify homologous recombinants, the endogenous CD4 protein is cleared from the surface of cells by endocytosis, whereas the CD4 epitopes derived from the fusion protein are retained and detected by flow cytometry. Verification is achieved by Southern blot analysis.

\section{Construction of the CD4/Thy-1 fusion and the targeting plasmid}

Figure 1A shows how the various domains of CD4, Thy-1, and the CD4/Thy-1 fusion proteins are presumed to be organized relative to the cell membrane. CD4 is proposed to consist of four extracellular domains (E1-E4) with varying degrees of homology to immunoglobulin $V$ and $I$ domains, a peptide transmembrane domain, and a short cytoplasmic carboxy-terminal region (Maddon et al. 1985, 1987). Thy-1 has one extracellular domain that is also homologous to immunoglobulin superfamily members (Campbell et al. 1981; Cohen et al. 1981; Williams and Gagnon 1982) and is anchored in the membrane by a glycosyl phosphatidyl inositol (GPI) tail (Low and Kincade 1985; Tse et al. 1985). The proposed CD4/Thy-1 fusion protein contains the E1 and E2 domains of CD4, the one extracellular domain of Thy-1, and the GPI membrane anchor.

The structures of the genes encoding the three proteins are shown in Figure 1B /Chang et al. 1985; Ingraham and Evans 1986; Maddon et al. 1987; D. Littman, pers. comm.). For both $C D 4$ and Thy-1, the first exon and most of the second consist of untranslated sequences. The remainder of exon 2 contains the leader sequence $(\mathrm{L})$, which directs the transport of the proteins to the cell surface. The sequence encoding the first CD4 extracellular domain $(E 1)$ is interrupted by a large intron. The other extracellular domains (E2-E4) are encoded by single exons. The last three exons $(8,9$, and 10$)$ encode the transmembrane and cytoplasmic domains and the 3 '-untranslated region. The Thy-1 extracellular domain $(V)$ and the GPI-tailed segment are encoded by exons 3 and 4 , respectively. The fusion gene contains exons 1-5 of the human CD4 gene joined to exons 3 and 4 of the Thy-1.2 allele of the mouse Thy-1 gene. The reading frame remains intact because an intron interrupts the codon at the same position in exons 5 and 6 of $C D 4$ as in exons 2 and 3 of Thy-1.

To test the stability and correct cell-surface expression of the fusion protein, an intact $C D 4 / T h y-1$ fusion gene was constructed and transiently transfected into COS-1 cells. Flow cytometry was performed on the transfected cells using the Leu3a and anti-Thy-1.2 antibodies, whose binding specificities are indicated in Figure 1A. Critical residues for the binding of Leu3a have been mapped to the E1 domain of $C D 4$, particularly residues that are encoded by exon 3 of $C D 4$ (Landau et al. 1988; Peterson and Seed 1988). This exon is included within the fusion gene (Fig. 1B). The anti-Thy-1.2 antibody recognizes the extracellular domain of Thy-1. Table 1 shows the results of the flow cytometric analysis of the transfected COS- 1 cells. A significant percentage of the cells transfected with the intact CD4/ Thy- 1 fusion gene were positive for the CD4 and Thy-1 epitopes, indicating that the fusion protein is made and transported to the cell surface.

The scheme for generating the fusion gene at the $C D 4$ locus is illustrated in Figure 2. The key feature is that the targeting plasmid pSE568 encodes Thy- 1 epitopes in an inexpressible form because it lacks the promoter, translation start site, and leader sequence upstream of the fusion sequence. In addition, $C D 4$ exon 3 , which encodes the amino-terminal Leu3a epitope of the fusion protein, is missing, facilitating the analysis presented below. The plasmid sequence shares homology with CD4 exons 4 and 5 over $3.3 \mathrm{~kb}$. The targeting plasmid
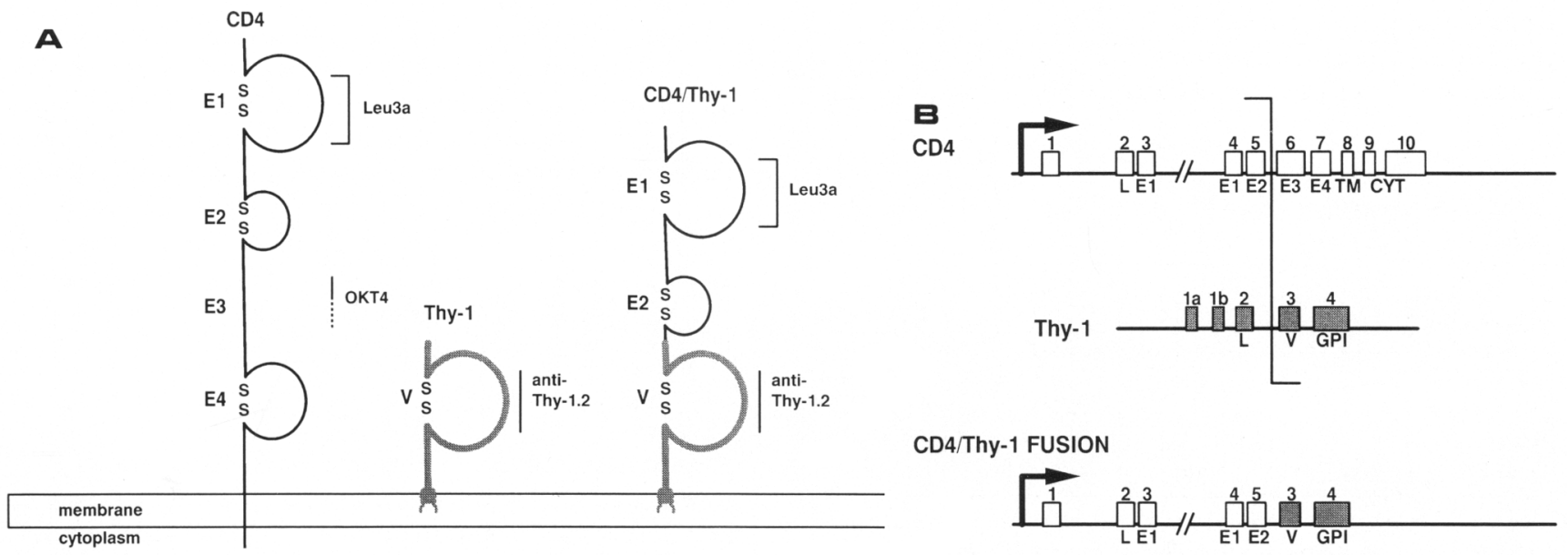

CD4/Thy-1 FUSION

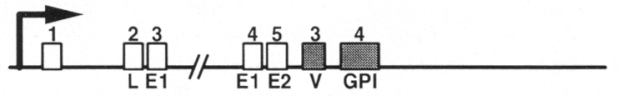

Figure 1. (A) Schematic diagrams of the human CD4 protein (modified from Bedinger et al. 1988), the Thy-1 protein, and the novel CD4/Thy-1 fusion. The binding sites of three monoclonal antibodies are indicated. $(B)$ Structures of the genes encoding the proteins. The vertical bar indicates where the fusion was made to generate the $C D 4 / T h y-1$ fusion gene. The gapped region indicates a large intron. (L) Leader peptide; (E and V) extracellular domains; (TM) transmembrane domain; (CYT) cytoplasmic domain; (GPI) glycosyl phosphatidyl inositol anchor. 


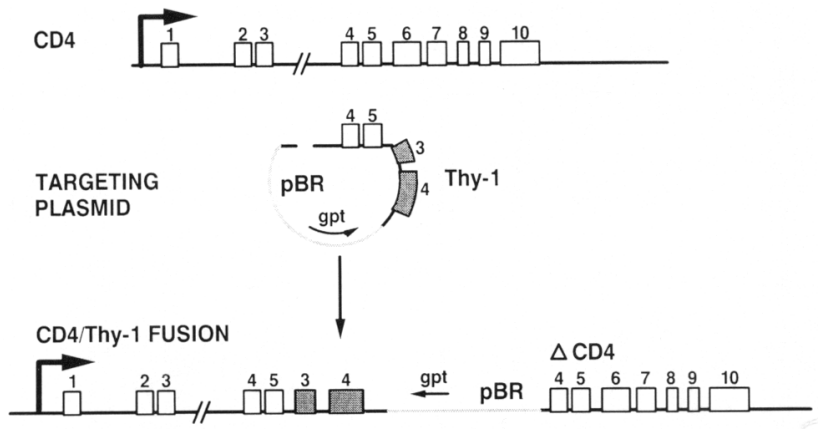

Figure 2. Scheme for homologous integration of the targeting plasmid at the $C D 4$ locus. In some cases, the targeting plasmid pSE568 is cleaved within the homology region prior to transfection.

also contains a functional gpt gene to permit selection of cells that have acquired the plasmid. Bacterial vector sequences are also included for recovery of integrated copies of the plasmid after transfection in Escherichia coli.

When transiently transfected into COS-1 cells, the targeting plasmid did not produce detectable amounts of either CD4 or Thy-1 cell-surface expression (Table 1). However, if the plasmid integrates at the CD4 locus in cells expressing CD4, as shown in Figure 2, we expect that the CD4/Thy-1 fusion protein would be produced and appear on the cell surface. Homologous recombination would also result in the truncation of the targeted CD4 gene at the $5^{\prime}$ end.

\section{Detection of homologous events}

The targeting plasmid was introduced into a human $\mathrm{T}$ cell line, JM, which expresses high levels of CD4 on the cell surface. Because Thy-1 is not a peripheral $\mathrm{T}$-cell marker in humans (Dalchau and Fabre 1979), Thy-1 expression would not be expected for these cells. Control transfections were carried out with plasmids containing the Thy-1 gene and the intact $C D 4 / T h y-1$ fusion gene. Three transfections were performed with the targeting

Table 1. Expression of the CD4/Thy-1 fusion protein on the surface of COS1 cells

\begin{tabular}{lcc}
\hline & \multicolumn{2}{c}{ Positive cells $|\%\rangle$} \\
\cline { 3 - 3 } Transfected DNA & Leu3a & anti-Thy-1.2 \\
\hline Mock & 0 & 0.04 \\
Thy-1 gene & 0.03 & 5.7 \\
Intact CD4/Thy-1 fusion gene & 13.9 & 12.2 \\
Crippled CD4/Thy-1 fusion gene & 0.01 & 0.04 \\
\hline
\end{tabular}

Cells were transiently transfected with plasmids containing no CD4 or Thy-1 gene (mock), the Thy-1 gene (pSV2-T8), an intact $C D 4 /$ Thy-1 fusion gene (pSE583), or a crippled CD4/Thy-1 fusion gene (pSE568). There is an SV40 replication origin on the latter three plasmids. FACS analysis was carried out $60 \mathrm{hr}$ posttransfection with either fluoresceinated Leu3a or anti-Thy-1.2 antibody. plasmid, one with supercoiled DNA, and two with linearized DNA. Because we had previously observed an enhancement of homologous versus nonhomologous events with a linear targeting plasmid (Jasin and Berg 1988), the DNA was cleaved with a restriction endonuclease in a region homologous to the chromosomal target (see Fig. 2). The cleavage divides the homology region into 0.4 and $2.9 \mathrm{~kb}$. To be able to isolate independent targeting events, cells were divided into 24 wells immediately after electroporation, each well containing $8 \times 10^{5}$ cells. Three days postelectroporation, gpt selection was imposed to select cells that had acquired the targeting plasmid. For each of the transfections, all of the wells were positive after the gpt selection. Because the transformation efficiency was at least $5 \times 10^{-5}$ (see Methods), each well was a pool of transformants.

Each pool of transformants was analyzed for Thy-1-expressing cells by flow cytometry, using the Fluorescence Activated Cell Sorter (FACS). Untransfected cells showed no Thy-1 expression on the cell surface (Fig. 3A). Cells transfected with plasmids containing either the Thy-1 gene or the intact CD4/Thy-1 fusion gene were primarily Thy-1 $1^{+}$, although the intensity of staining varied considerably within the population of transfected cells (data not shown). The FACS profiles of most of the pools of transformants derived from transfection with the targeting plasmid were identical to the untransfected cells. Several pools did, however, contain a small percentage of Thy-1 $1^{+}$cells, three of which are shown in Figure 3A. An expanded version of the lower portion of the FACS profiles is shown in Figure 3B. A summary of these results is presented in Table 2.

On the basis of the large number of pools that did not express Thy-1 and analyses described below, the Thy-1 ${ }^{+}$ cells in each positive pool were probably derived from a single transformant. On average, the Thy- $1^{+}$cells were $\sim 1 \%$ of the cells in a pool, suggesting that there were $\sim 100 \mathrm{gpt}^{+}$transformants per well. Therefore, the $\mathrm{gpt}^{+}$ transformation efficiency was $\sim 1 \times 10^{-4}$, consistent with the lower limit of $5 \times 10^{-5}$, based on cell dilution.

Several Thy $-1^{+}$cells were cloned from each positive pool of transformants. FACS analyses for some of the clones are shown in Figure 3C. The level of Thy-1 cellsurface expression varied between clones from different pools, but was similar for clones derived from the same pool. Typically, two to four clones from each pool were analyzed by the flow cytometry and Southern analyses described below. Identical results were obtained for all Thy-1 ${ }^{+}$clones derived from the same pool.

\section{Identification of homologous integrants}

Because homologous integrants would be expected to have one allele of $C D 4$ expressing the CD4/Thy-1 fusion protein and one allele expressing the endogenous CD4 protein, they could not be screened directly for a Thy $-1+{ }^{+}$CD4- phenotype. Instead, potential homologous integrants were identified on the basis of a differential behavior of the CD4 and Thy-1 proteins when cells were treated with phorbol esters. The addition of phorbol 

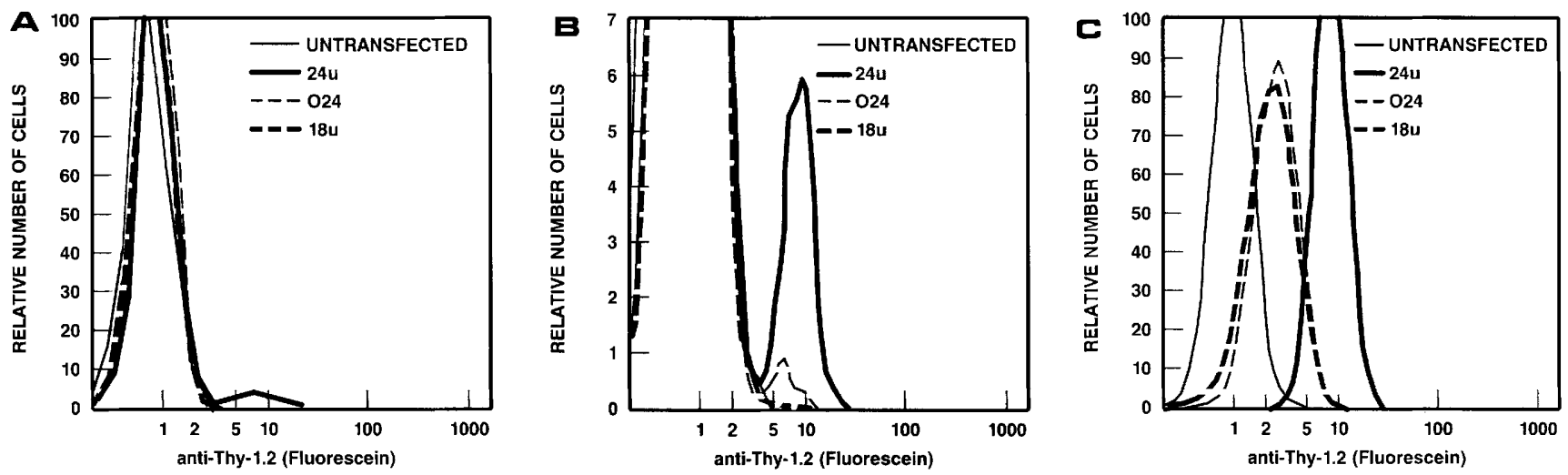

Figure 3. FACS analysis for Thy-1 expression of gpt ${ }^{+}$pools $(A$ and $B)$ and clones derived from those pools $(C) .(B)$ Expansion of the lower portion of the analysis in $A$. The main peaks in $A$ and $B$ are superimposable, but they are slightly offset from each other for clarity.

esters leads to the phosphorylation of cytoplasmic CD4 residues and subsequently to its internalization (Acres et al. 1986; Hoxie et al. 1986). Being anchored in the membrane by a GPI tail, neither Thy-1 nor the fusion protein is internalized following phorbol ester treatment (data not shown). Therefore, the cell-surface expression of CD4 epitopes contained within the E1 and E2 domains, following the addition of phorbol esters, is diagnostic for the presence of the fusion protein.

The positions of binding sites for antibodies used in this analysis are shown in Figure 1A. In addition to the Leu3a and anti-Thy-1.2 antibodies, the OKT4 antibody was also used, as it can distinguish between the CD4/ Thy- 1 fusion and endogenous CD4. The binding site for OKT4 is carboxy-terminal to the E2 domain (Landau et al. 1988) and is therefore absent from the fusion protein. The predictions of this analysis are listed in Table 3. Following the addition of phorbol esters to cells, there would be no change in the intensity of anti-Thy-1.2 staining for any of the Thy-1+ clones, whereas staining of the endogenous CD4 protein by Leu3a and OKT4 would be severely reduced. However, clones expressing the fusion protein, either from transformation with the intact fusion gene or as the result of homologous integration of the targeting plasmid, would continue to stain with Leu3a, although to a lesser extent.

Cells were incubated for $4 \mathrm{hr}$ with or without the phorbol ester phorbol-12,13-dibutyrate (PDB) and ana- lyzed for cell-surface expression of the three epitopes. Untransfected JM cells were primarily positive for both CD4 epitopes, although a few percent were negative for both (Fig. 4). In contrast, much of the antibody staining was absent after incubation with phorbol esters. For each of the Thy-1 ${ }^{+}$clones, there was little or no change in the level of expression of the Thy-1 epitope (data not shown). Clones derived from transformation with the Thy-1 gene were similar to the untransfected cells with regard to Leu3a and OKT4 staining, whereas clones derived from transformation with the intact $C D 4 / T h y-1$ fusion retained a significant fraction of Leu3a staining, the level depending on the amount of the fusion protein being expressed in these cells (data not shown). FACS analyses of Thy- $1^{+}$clones derived from transfection with the targeting plasmid are shown in Figure 4, A and B. Clone $24 \mathrm{u}$, as well as $12 \mathrm{u}$ and $\mathrm{O} 3$ (data not shown), cisplayed a pattern similar to the untransfected cells, suggesting that they were derived from nonhomologous integration of the plasmid. Clone $\mathrm{O} 24$, as well as $15 \mathrm{u}$, $\mathrm{O} 10$, and $\mathrm{O} 22$ (data not shown), gave patterns consistent with a homologous integration at one of the $C D 4$ alleles. Both anti-CD4 antibodies stained the cells prior to phorbol ester addition, but only half of the Leu3a staining remained after phorbol ester treatment. Clone $18 \mathrm{u}$ shows a surprising staining pattern in that there is no OKT4 staining with or without phorbol ester addition (Fig. 4B). However, the Leu3a epitope remained, and

Table 2. Summary of stable transformations of the human $T$-cell line $I M$ with the targeting plasmid

\begin{tabular}{|c|c|c|c|}
\hline \multirow[b]{2}{*}{ Targeting plasmid $(\mu \mathrm{g})$} & \multicolumn{2}{|c|}{ Positive wells } & \multirow{2}{*}{$\begin{array}{c}\text { Percent of Thy-1+ cells } \\
\text { per positive well (well name) }\end{array}$} \\
\hline & $\mathrm{gpt}^{+}$ & $\overline{\text { Thy-1+ }}$ & \\
\hline Supercoiled (100) & 24 & 5 & $0.12(12 u), 0.63(15 u), 0.30(16 u), 0.06(18 u), 3.16(24 u)$ \\
\hline Linearized $(100)$ & 24 & 5 & $0.60(\mathrm{O} 1), 0.07(\mathrm{O} 3), 1.48(\mathrm{O} 10), 2.71(\mathrm{O} 22), 0.62(\mathrm{O} 24)$ \\
\hline Linearized $(200)$ & 24 & 1 & $0.72(\mathrm{~T} 3)$ \\
\hline
\end{tabular}

Cells were divided into 24 wells immediately after electroporation and selected for gpt expression. Subsequently, $10^{4}$ gpt $^{+}$cells from each well were analyzed by flow cytometry for the expression of the Thy-1 epitope on the cell surface. Wells were considered positive if they consistently had significantly more cells in the positive range than the untransfected control (i.e., $>0.03 \%$ in the fluorescein intensity range above 5 , as shown in Fig. 3). The percentage of Thy-1 ${ }^{+}$cells from each positive well is given, together with the designation given to that well. This designation is also used for Thy- $1^{+}$clones subsequently derived from that well. 
Table 3. Expectations for antibody reactivity of various cell types in the absence or presence of phorbol esters

\begin{tabular}{|c|c|c|c|c|c|c|}
\hline & \multicolumn{3}{|c|}{ - Phorbol ester } & \multicolumn{3}{|c|}{+ Phorbol ester } \\
\hline & anti-Thy-1.2 & Leu3a & OKT4 & anti-Thy-1.2 & Leu3a & OKT4 \\
\hline Untransfected cells & - & ++ & ++ & - & - & - \\
\hline \multicolumn{7}{|l|}{ Control transformants } \\
\hline Thy-1 & + & ++ & ++ & + & - & - \\
\hline CD4/Thy-1 fusion & + & +++ & ++ & + & + & - \\
\hline \multicolumn{7}{|c|}{ Thy-1+ transformants (targeting plasmid) } \\
\hline nonhomologous integrants & + & ++ & ++ & + & - & - \\
\hline homologous integrants & + & ++ & + & + & + & - \\
\hline
\end{tabular}

Each plus sign represents the cell-surface expression from one allele. The control CD4/Thy-1 fusion transformants have additional Leu3a binding, the level of which varies among the different transformants.

its level did not change with phorbol ester treatment. Two other clones, $16 \mathrm{u}$ and $\mathrm{Ol}$, gave similar patterns (data not shown). This suggests that CD4 is absent in these clones and that only the CD4/Thy-1 fusion protein is present on the cell-surface.

\section{Southern analysis}

Southern analysis of the recovered clones' genomic DNA was used to check the interpretation of the flow cytometry results. Restriction endonuclease analyses were designed to detect a linkage between the targeting plasmid and the CD4 locus (Fig. 5). The 5' junction of the chromosomal DNA and the targeting plasmid, the junction that creates the fusion gene, was examined using probes derived from the Thy- 1 gene and from CD4 intron 3 (5' probe, Fig. 5). The $3^{\prime}$ junction was analyzed using probes derived from the pBR322 vector and from CD4 intron 5 and exon $6\left(3^{\prime}\right.$ probe, Fig. 5). Both of the $C D 4$ probes are specific for the chromosomal CD4 locus and do not hybridize to the targeting plasmid.

Digestion of cellular DNAs with EcoRI endonuclease allowed the analysis of the $5^{\prime}$ junction (Fig. 6). A novel 10.2-kb CD4 fragment is diagnostic of the predicted ho- mologous integrants. The untransfected JM cells yielded a very large $E$ coRI fragment $(>20 \mathrm{~kb})$ that hybridized to the $C D 4$ probe, but no hybridization was detected with the Thy- 1 probe. Thy- $1^{+}$clones $24 \mathrm{u}$ and $\mathrm{O} 3$ (plus $12 \mathrm{u}$; not shown/ also generated the one large EcoRI band with the CD4 probe. Only smaller bands were detected by hybridization with the Thy-1 probe. This is consistent with the interpretation drawn from the FACS analysis: These clones were most likely derived from nonhomologous integration of the introduced plasmid.

DNAs from the remaining eight Thy-1 ${ }^{+}$clones yielded two bands after EcoRI digestion and hybridization with the 5'CD4 probe: the $>20-\mathrm{kb}$ band and an $\sim 10-\mathrm{kb}$ band (Fig. 6). Hybridization of the same blots with the Thy-1 fragment also labels the $10-\mathrm{kb}$ band. These results are consistent with the interpretation of the FACS analysis that these clones were derived from homologous integration of the targeting plasmid. Because both the endogenous CD4 band, as well as the novel band, were produced from each of these clones, the integration appears to have occurred in only one of the two CD4 alleles. In clones that express no CD4 protein (e.g., 18u; Fig. 4), the endogenous CD4 allele must be nonfunctional. The nature of the defect in these
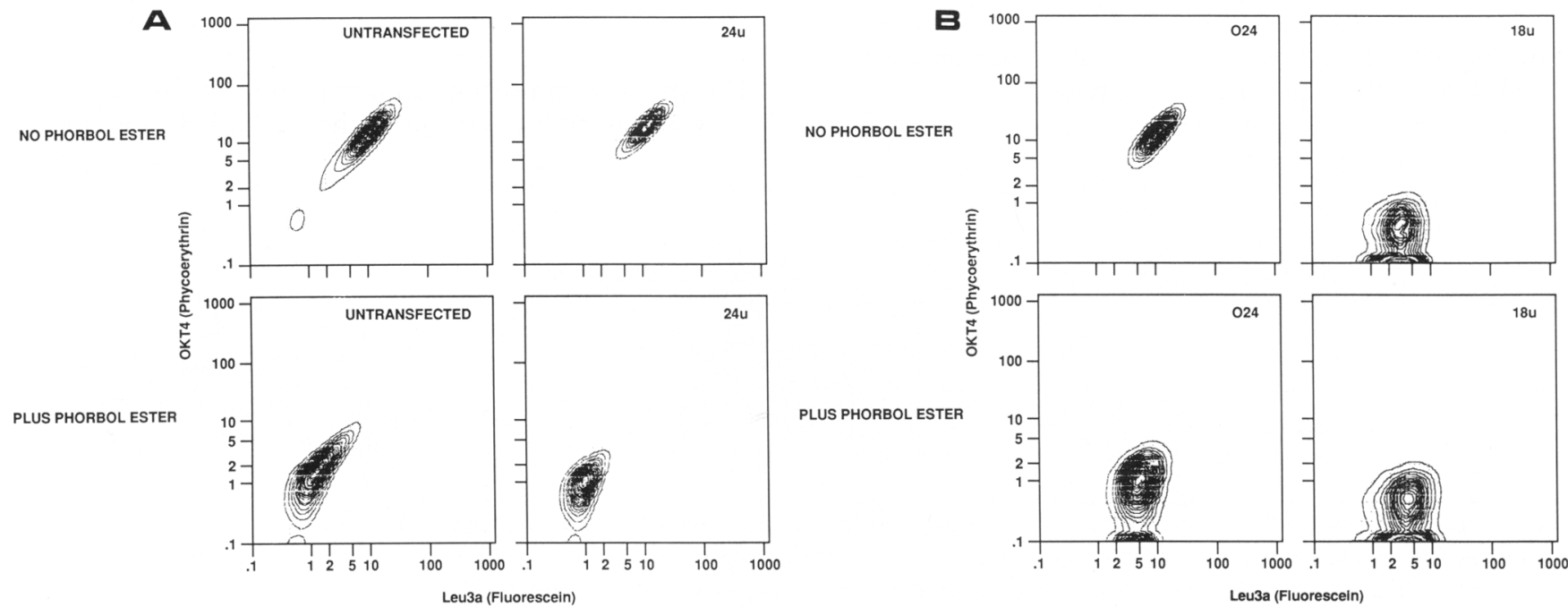

Figure 4. FACS analysis of Thy-1+ clones in the absence (top) or presence (bottom) of phorbol esters. 


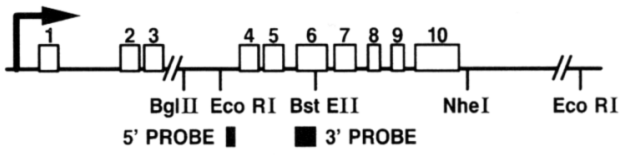

Figure 5. Restriction map of the $C D 4$ locus and the CD4/Thy-1 fusion locus. Only relevant sites are shown. The light and dark shaded areas indicate the targeting plasmid-derived sequences and the homology regions, respectively. The bar above the $C D 4 / T h y-1$ fusion represents the BamHI fragment recovered from genomic DNA of Thy-1 $1^{+}$clones $18 \mathrm{u}$ and $\mathrm{O} 24$ through cloning in E. coli. It extends $\sim 200 \mathrm{bp}$ beyond the homology region.

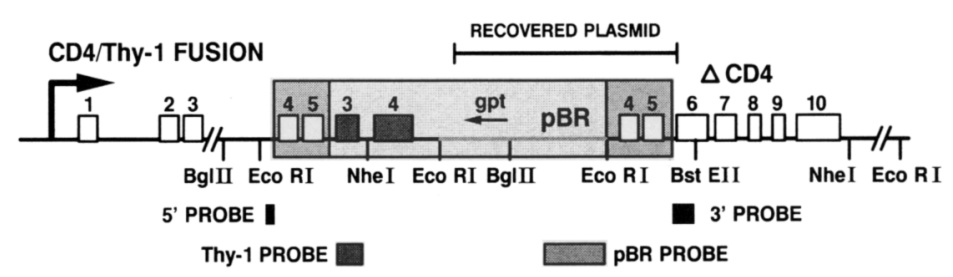

clones has not been determined. The $5^{\prime}$ junction was also analyzed by a second digest, BgIII-NheI, using the same probes (for the position of these sites, see Fig. 5.). Results identical to the EcoRI analysis were obtained (data not shown).

A second, smaller band was detected with the Thy-1 probe in the EcoRI digest from some of these clones (15u, 16u, O24, and T3; Fig. 6). The size of this band 16.9 $\mathrm{kb})$ was the same as that of the EcoRI fragment generated from the incoming plasmid DNA. Therefore, it is possible that a second copy of the target plasmid may have integrated at the CD4 locus. Alternatively, a second, nonhomologous integration of the plasmid may have occurred elsewhere in the genome. Additionally, clone T3 had a third band of intermediate size, the origin of which has not been determined.

To analyze the $3^{\prime}$ junction of plasmid and chromosomal DNA, genomic DNA was cleaved with BgIII and BstEII endonucleases (Fig. 5). The 3' CD4 probe hybridized to an $29.4-\mathrm{kb}$ band with DNA from untransfected cells (Fig. 7). The pBR probe did not hybridize to this DNA. Homologous integrants should yield a band of 6.5 $\mathrm{kb}$. As expected, each of the Thy-1+ clones produced a 9.4-kb band from the unaltered $C D 4$ locus. However, in contrast to the results with the $5^{\prime}$ probe, hybridization with the $3^{\prime}$ probe showed that only three homologous integrants (O24 and 18u; Fig. 7; 16u; data not shown) produced the predicted sized band. In these cases, this band also hybridized with the pBR probe. For three other homologous integrants $(\mathrm{O} 10, \mathrm{O} 22$, and $15 \mathrm{u})$, there was no second band with the $3^{\prime} C D 4$ probe; and for O10 and $\mathrm{O} 22$, there was also no hybridization with the $\mathrm{pBR}$ probe. This suggests that the expected $3^{\prime}$ junction was deleted (or never formed) in these recombinants, removing $\mathrm{pBR}$ and some $C D 4$ sequences but leaving gpt and $C D 4 /$ Thy 1 sequences intact. In clone $15 \mathrm{u}$, the deletion appears to be more restricted in that only the $C D 4$ junction sequences were removed and the pBR sequences were retained. The $3^{\prime}$ probe detects a new band with three other clones, $\mathrm{O} 1, \mathrm{~T} 3$, and 16u (not shown). In these instances, the recombination appeared to have been accompanied by a rearrangement of sequences at the $3^{\prime}$ junction. These putative deletions and rearrangements at the $3^{\prime}$ junction would not have affected the sequences needed for gpt selection or the Thy-1 screen.

To test further the structure of the homologous integration sites, this region was cloned from two of the homologous recombinants. Genomic DNA from clones $18 \mathrm{u}$ and $\mathrm{O} 24$ was digested with BamHI to retrieve a recombinant segment (Fig. 5). This fragment contains pBR, $g p t$, and $3^{\prime}$ homologous junction sequences. In addition, it includes $C D 4$ intron 5 sequences that are not present

Figure 6. Southern blot analysis to detect the $5^{\prime}$ integration site junction from Thy-1+ clones. Genomic DNA was cleaved with EcoRI and probed as indicated. JM designates the untransfected cells. Sizes of marker DNAs are derived from restricted $\lambda$ phage DNA.

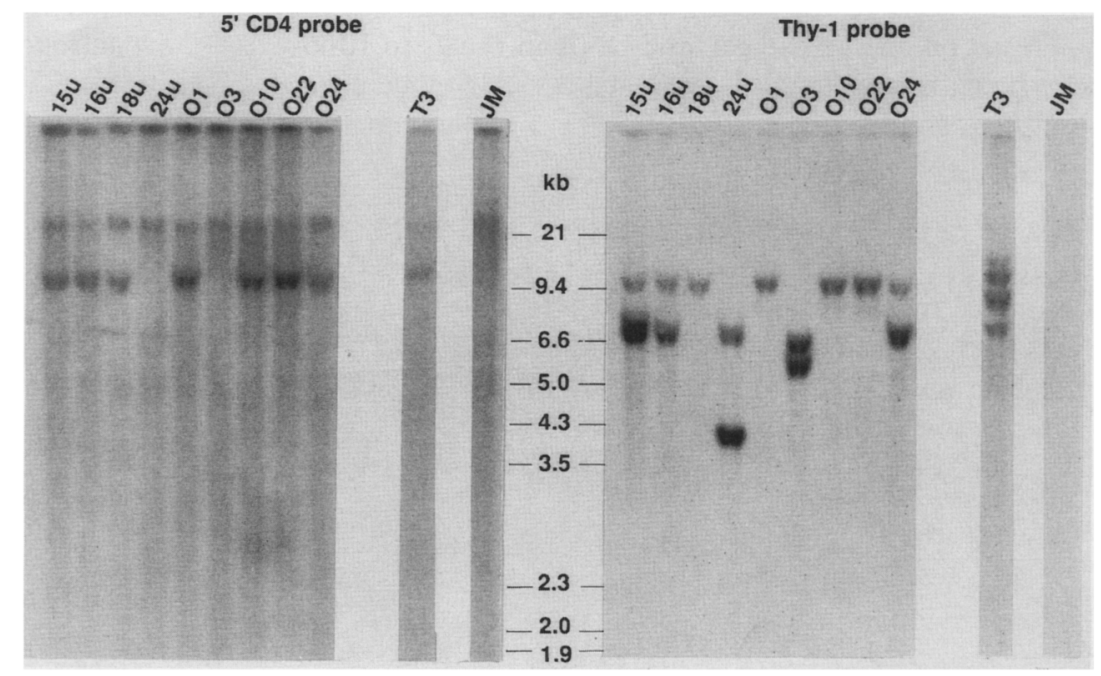




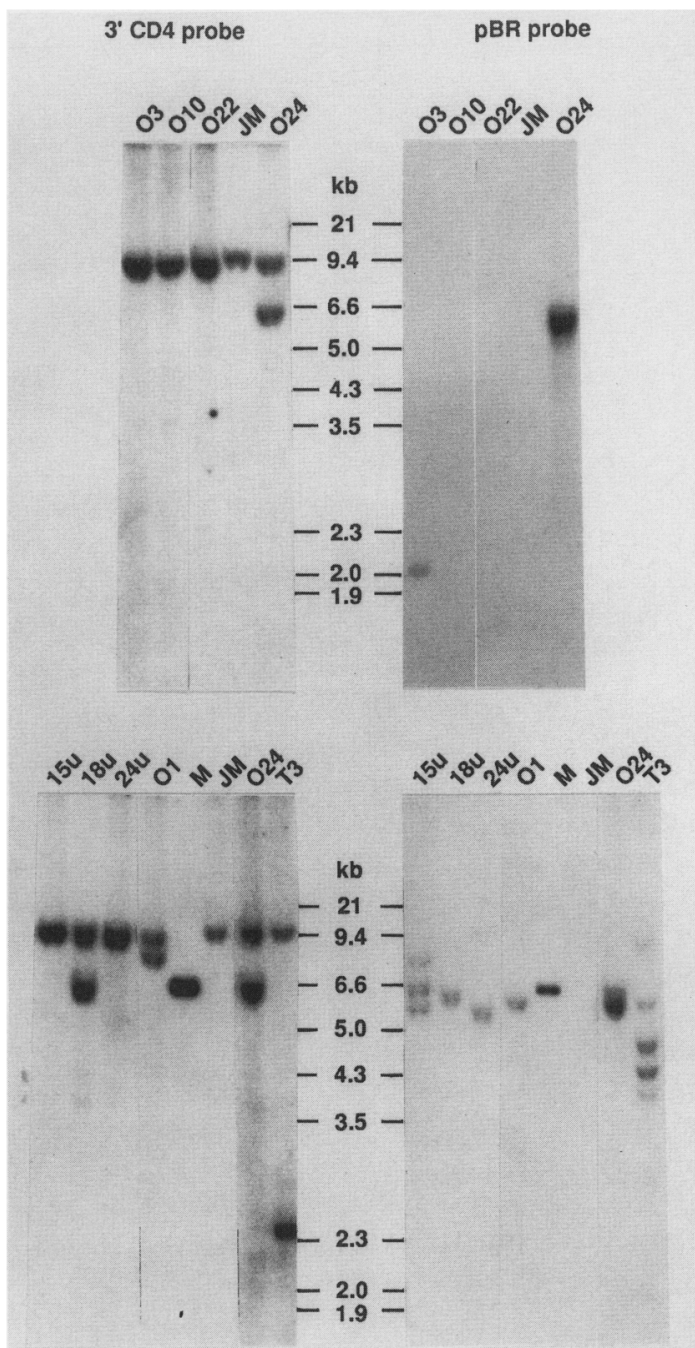

Figure 7. Southern blot analysis to detect the $3^{\prime}$ integration site junction from Thy $-1^{+}$clones. Genomic DNA was cleaved with BgIII-BstEII and probed as indicated. (Lanes $M-$ The 6.6$\mathrm{kb}$ size marker derived from plasmid DNA containing the $C D 4$ 3' probe.)

on the targeting plasmid. The BamHI digest was electrophoresed on an agarose gel, and DNA in the $7-$ to $10-\mathrm{kb}$ size range was isolated, ligated at low DNA concentration, and transfected into $E$. coli. Ampicillin-resistant colonies were isolated, and their plasmid DNA was purified. Restriction and Southern blotting analyses of the recovered plasmid DNA from both $18 \mathrm{u}$ and $\mathrm{O} 24$ were consistent with the predicted recombinant arrangement shown in Figure 5. In addition, a plasmid was isolated from $\mathrm{O} 24$, which appeared to be derived from the input targeting plasmid. This is consistent with the previous interpretation of Figure 6 that clone O24 has a second copy of the targeting plasmid at the integration site.

Table 4 summarizes the combined findings obtained by flow cytometry and Southern analyses. Eleven Thy $-1^{+}$clones were recovered, eight of which were derived from gene targeting at the CD4 locus. Five of the homologous integrants expressed both the novel CD4/
Thy-1 fusion protein and the endogenous CD4 protein, whereas three expressed only the fusion protein. When uncut plasmid DNA was transfected, three of the five Thy-1 ${ }^{+}$transformants were homologous integrants. With linearized DNA, five of six Thy $-1^{+}$transformants were homologous integrants. On the basis of our estimate of $2500 \mathrm{gpt}^{+}$transformants per transfection, the ratio homologous to nonhomologous integration (targeting index $\mid$ is $\sim 1 / 900$, with an overall frequency of one homologous integrant per $8 \times 10^{6}$ cells exposed to DNA.

\section{Discussion}

In the experiments presented, human CD4 epitopes were replaced with murine Thy-1 epitopes in the creation of a CD4/Thy-1 fusion protein through a novel gene targeting approach. Seventy percent of the Thy-1+ transformants were derived from homologous integration events at the $C D 4$ locus. The high efficiency was achieved as a consequence of the design of the targeting plasmid. The Thy-1 gene on the targeting plasmid is severely crippled; it contains no promoter, translation start, or leader sequence for transport of the protein to the cell-surface. Homologous integrations, unlike most nonhomologous events, lead to expression of Thy-1 epitopes on the cell-surface (epitope addition). The 11 Thy-1 ${ }^{+}$transformants were isolated from $\sim 7500 \mathrm{gpt}^{+}$ transformants, suggesting that this scheme led to a $700-$ fold enrichment for homologous recombinants.

The estimated ratio of homologous to nonhomologous integration events $(1 / 900)$ is similar to that seen at other loci in mammalian cells. The region spanning exons 4 and 5 of $C D 4$ contains highly repetitive sequences; therefore, the presence of repetitive elements may have only a small or negligible effect on the targeting efficiency. The divergent sequences of repetitive elements may be significant enough so as not to promote recombination. Linearizing the targeting plasmid had only a marginal effect on the targeting efficiency. This contrasts with our previous experiments in which at least a sixfold enhancement was observed by cutting within the homology region (Jasin and Berg 1988). It is possible that the electroporated $T$ cells process incoming DNA differently from the calcium phosphate-treated COS-1 cells.

Homologous integrants had restriction patterns at the $5^{\prime}$ junction of the integration site consistent with the crossover diagrammed in Figure 2. It is this junction that creates the fusion protein; however, the predicted $3^{\prime}$ junction was present in only a few of the cell lines. It is not known whether this junction was formed during integration and subsequently deleted or rearranged, or whether the initial integration was a variation of that shown in Figure 2. There is no selection for the maintenance of this junction, although there may be a selective advantage to its loss, as cells having lost the junction would not be able to delete the targeting plasmid, including the gpt gene, by the reverse of the crossover indicated in Figure 2. Similar structures have been reported at integration sites derived from other gene-tar- 
Table 4. Summary of Thy-1+ clones

\begin{tabular}{|c|c|c|c|c|}
\hline \multirow[b]{2}{*}{ Integrants $^{\mathbf{a}}$} & \multicolumn{2}{|c|}{ FACS analysis ${ }^{b}$} & \multicolumn{2}{|c|}{ Southern analysis ${ }^{c}$} \\
\hline & $\mathrm{CD}^{+}+$ & $\overline{\text { CD4/Thy-1 }}{ }^{+}$ & $\overline{5^{\prime} C D 4 \text { probe }}$ & 3' $C D 4$ probe \\
\hline \multicolumn{5}{|l|}{ Nonhomologous } \\
\hline $\mathrm{O} 3,12 \mathrm{u}, 24 \mathrm{u}$ & + & - & $\mathrm{E}$ & $\mathbf{E}$ \\
\hline \multicolumn{5}{|l|}{ Homologous } \\
\hline $\mathrm{O} 24$ & + & + & $\mathrm{E}, \mathrm{H}$ & $\mathrm{E}, \mathrm{H}$ \\
\hline $\mathrm{T} 3$ & + & + & $\mathrm{E}, \mathrm{H}$ & E, N \\
\hline $010,022,15 u$ & + & + & E, H & E \\
\hline $18 \mathrm{u}$ & - & + & E, H & E, $\mathrm{H}$ \\
\hline Ol & - & + & E, H & $\mathrm{E}, \mathrm{N}$ \\
\hline $16 \mathrm{u}$ & - & + & E, H & $\mathrm{E}, \mathrm{H}, \mathrm{N}$ \\
\hline
\end{tabular}

aClones designated $\mathrm{O}$ or $\mathrm{T}$ are derived from transfection with 100 or $200 \mu \mathrm{g}$ of linearized targeting plasmid DNA, respectively. Those designated $\mathrm{u}$ are derived from transfection with $100 \mu \mathrm{g}$ of uncut targeting plasmid DNA.

bClones positive for the CD4/Thy-1 fusion protein (homologous integrants) and the endogenous CD4 protein are assigned according to the analysis described in the text and shown in Fig. 4.

cAccording to the analysis described in the text and shown in Figs. 5-7: (E) Presence of the endogenous CD4 fragment; (H) expected homologous recombinant fragment; $(\mathrm{N})$ a novel fragment.

geting events (Thompson et al. 1989; Ellis and Bernstein 1989).

As a result of targeting, an allele of $C D 4$ is disrupted with the creation of the $C D 4 /$ Thy-1 fusion gene. Three cell lines were isolated that express the fusion protein in the absence of detectable expression of CD4 protein from the second allele. Although the nature of the defect at the second allele is not known, the isolation of such lines suggests that it may not always be necessary to undertake two successive rounds of gene targeting to obtain cell lines exclusively expressing an altered protein. Our scheme for gene targeting resulted in each allele of CD4 being distinctly marked. It is possible that cell lines derived from gene targeting into other diploid loci are similarly functionally hemizygous. The lines expressing only the CD4/Thy-1 fusion protein will be analyzed for their ability to undergo normal T-cell activation and tested for HIV infectability.

The nature of the three nonhomologous integration events that give rise to Thy-1 epitopes on the cell-surface has not been explored. Presumably, integration in these cases resulted in the Thy-1 exons residing in a locus that could donate transcription signals and a leader sequence to the crippled Thy-1 gene. This could have resulted in either a gene or protein fusion, possibly mutagenizing another chromosomal locus.

Epitope addition makes it possible to tag chromosomal loci with easily scorable markers. In the example shown here, epitopes of CD4 were replaced with those from Thy-1. For loci that do not encode cell-surface proteins, a crippled cell-surface marker can be introduced, together with its leader sequence, in a discistronic configuration (Jasin and Berg 1988). $\beta$-Galactosidase could also be used for tagging loci through gene targeting, and it may have an advantage in that it functions easily as a fusion protein. As with cell-surface markers, its expression can be monitored by flow cytometry (Nolan et al. 1988), as well as with in situ staining.

In addition to gene targeting, epitope addition may facilitate the characterization of other cellular processes.
Interchromosomal recombination at different loci can be studied in cells that have each allele marked with a distinct epitope. By analogy to bacterial and yeast expression studies (e.g., with $\beta$-galactosidase), factors that influence the transcription of a locus can be explored independently from those that affect protein stability. In particular, the involvement of distant cis-acting sites in transcription can be monitored with a tag at the normal chromosomal locus. In the enrichment of homologous recombinants, epitope addition requires that the locus be expressed. Gene targeting resulting in epitope addition at nonexpressed loci could be detected by DNA screening protocols. Loci that have regulated expression during differentiation or development may be of particular interest to mark in this manner (Gossler et al. 1989; Kerr et al. 1989).

\section{Methods}

\section{Cell growth and transfection}

COS-1 cells were cultured and transfected as described previously (Jasin and Berg 1988). The human T-cell line JM, which was obtained from the Stanford Blood Bank, was cultured in RPMI (GIBCO) containing 10\% fetal calf serum and penicillin/ streptomycin. Cells were grown to a density of $10^{6} / \mathrm{ml}$, centrifuged, and resuspended in $1 \times \mathrm{HeBS}$ buffer (Chu et al. 1987). In the apparatus described by Chu et al. (1987), $2 \times 10^{7}$ cells were electroporated in a volume of $0.8 \mathrm{ml}$ with 100 or $200 \mu \mathrm{g}$ targeting plasmid DNA at $1080 \mu \mathrm{F}(260 \mathrm{~V})$. Control transfections contained $70 \mu \mathrm{g}$ of the Thy-1 gene plasmid, $70 \mu \mathrm{g}$ of RSVgpt (Gorman et al. 1983) cotransfected with $100 \mu \mathrm{g}$ of the intact $C D 4 / T h y-1$ gene plasmid and, for the mock transfection, $70 \mu \mathrm{g}$ of an unrelated plasmid, pEnd. Cells were diluted into a 24-well tissue culture plate (Falcon) with $8 \times 10^{5}$ cells in $1.5 \mathrm{ml}$ of media per well. Further dilutions were made with the two transfections with linearized targeting plasmid DNA so that each of 12 wells contained $4.5 \times 10^{4}$ cells and another 12 wells each contained $2.2 \times 10^{4}$ cells. The $\mathrm{gpt}^{+}$transformants were selected in media containing $200 \mu \mathrm{g} / \mathrm{ml}$ xanthine, $150 \mu \mathrm{g} / \mathrm{ml}$ glutamine, $10 \mu \mathrm{g} / \mathrm{ml}$ hypoxanthine, and $1 \mu \mathrm{g} / \mathrm{ml}$ mycophenolic acid. The selection was initiated 3 days postelectroporation by removing $0.75 \mathrm{ml}$ media from the cells and adding $0.75 \mathrm{ml}$ of 
the selective medium. This was repeated every 3-4 days. At 20 days postelectroporation, cells were transferred to larger plates and cultured for another 4-17 days until cells were frozen and Thy-1 $1^{+}$cells were cloned. For each of the transfections, all 24 wells containing $8 \times 10^{5}$ cells were positive after gpt selection. In addition, for the transfection with $200 \mu \mathrm{g}$ linearized targeting plasmid DNA, all of the wells with higher dilutions $4.5 \times 10^{4}$ and $2.2 \times 10^{4}$ cells per well) were also positive. For the transfection with $100 \mu \mathrm{g}$ linear DNA, all but one of the wells were positive. The one negative well was derived from $2.2 \times 10^{4}$ cells. The gpt transformation efficiency is therefore $>5 \times 10^{-5}$. Cells were cloned with the FACS into 96-well tissue culture plates (Falcon) into selective or nonselective media containing $20 \%$ fetal calf serum. Nonselective media were identical to selective media, except the former contained no mycophenolic acid. Subsequent passaging was into selective media.

\section{Antibody staining and FACS}

Cells for staining were washed and resuspended at a concentration of $10^{7} / \mathrm{ml}$ in RPMI-deficient medium containing 3\% fetal calf serum, $10 \mathrm{mM}$ HEPES $(\mathrm{pH} 7.2)$, and $0.1 \%$ sodium azide (staining media). For analysis, $50 \mu \mathrm{l}$ of cells was mixed with 50 $\mu \mathrm{l}$ of the antibody diluted in staining media. Fluorescein-conjugated Leu3a and anti-Thy-1.2 antibodies were supplied by Becton-Dickinson; phycoerythrin-conjugated OKT4 was supplied by Ortho Diagnostic Systems. Dilutions were made according to the suppliers' recommendations. Incubations were for 15-30 min on ice. Cells were rinsed twice with staining media, resuspended in $500 \mu \mathrm{l}$, and filtered through nylon mesh. For sorting, a larger volume of cells was processed essentially the same way. FACS runs were as described (Parks et al. 1986), and multiparameter data were collected and analyzed by using FACS-DESK run on a Digital VAX-780 (Moore and Kautz 1986). The phorbol ester PDB was used at a concentration of $1 \mu \mathrm{M}$ at $37^{\circ} \mathrm{C}$.

\section{Recombinant DNA constructs and techniques}

All DNA constructs were made by standard recombinant DNA techniques under conditions conforming to the National Institutes of Health Guidelines for Recombinant DNA Research. A 3.5-kb EcoRI-BamHI fragment spanning CD4 exons 4 and 5 had previously been cloned into pUC8 (D. Littman, pers. comm.). The $H p a I-B a m H I$ vector fragment of this plasmid was ligated to a SmaI-BgIII fragment containing exons 2 and 3 of the murine Thy-1.2 gene. The Thy-1 fragment was generated by EcoRI digestion of pSV2-T8 (Evans et al. 1984), fill-in of the ends with Klenow fragment, addition of BgIII linkers, SmaI digestion, and isolation of the $3.6-\mathrm{kb} S m a I-B g l I I$ fragment. The targeting plasmid pSE568 was constructed by cloning the EcoRI fragment containing the CD4/Thy-1 fusion into pSE567, a modified version of pSV2gpt (Mulligan and Berg 1980), which was made by destroying the HindIII site by a Klenow fill-in reaction. For transfections with linearized DNA, the plasmid was cleaved with HindIII, which cuts $\sim 420$ bp from the end of the homology region. An intact $C D 4 / T h y-1$ fusion gene plasmid (pSE583) was constructed by partially cleaving pSE568 with SacI (which cleaves within exon 5 of $C D 4$ ) and Sall (which cleaves in the polylinker adjacent to the EcoRI site) and ligating this fragment to the vector SacI-SalI fragment of SV7dT4 (D. Littman, pers. comm.|, which contains the CD4 cDNA transcribed from the $S V 40$ promoter. The intact fusion gene therefore consists of $C D 4$ cDNA sequences from exons $1-5$, intron 5 sequences up to the Hpal site, and Thy-1 genomic sequences spanning exons 3 and 4.
Southern analysis (Southern 1975) was performed essentially according to Maniatis et al. (1982), using modifications suggested by the manufacturer of GeneScreen Plus (DuPont). Probes were radiolabeled using the hexamer labeling technique (Feinberg and Vogelstein 1983). The Thy-1 probe is the 680-bp SmaI-NheI fragment from pSV2-T8 (Chang et al. 1985). The 5' CD4 probe is an $\sim 600$-bp NcoI fragment upstream from the $C D 4$ fragment contained in the targeting plasmid. The $3^{\prime}$ CD4 probe is a 460-bp BamHI-BstEII fragment, which is $200 \mathrm{bp}$ downstream of the $C D 4$ fragment contained in the targeting plasmid and overlaps the intron 5/exon 6 border. The pBR probe is pIC-20H (Marsh et al. 1984).

The 3 ' junction was isolated from clones $18 \mathrm{u}$ and $\mathrm{O} 24$ by cleaving $10 \mu \mathrm{g}$ of genomic DNA with BamHI, electrophoresing the DNA on a $0.8 \%$ agarose gel, and isolating fragments in the 7- to 10-kb size range. Approximately $50 \mathrm{ng}$ of the isolated DNA was ligated in $450 \mu \mathrm{l}$. From this, $6 \mathrm{ng}$ was transformed into $E$. coli selecting for ampicillin resistance. Four colonies arose from 18u DNA and two from O24. Plasmids were analyzed by a series of digests, and gel electrophoresis was followed by Southern hybridizations. A 200-bp CD4 HpaI-BamHI fragment from directly downstream of the homology region on the targeting plasmid was used as probe.

\section{Acknowledgments}

We are grateful to Dan Littman for helpful discussions and plasmid DNA. In addition, we thank Jack Silver and Glen Evans for plasmid DNA, members of the Herzenbergs' laboratory, particularly, Steve Fiering and Garry Nolan, for help with the cell sorter, and Heidi Stuhlmann, Brian Pontius, Ned Landau, and Ian Chambers for comments on the manuscript. M.J. was a fellow of the Jane Coffin Childs Memorial Fund for Medical Research when this work was initiated; S.J.E. was a Helen Hay Whitney Fellow and an American Cancer Society Senior Fellow. This work was supported by grant GM-13235-23 from the National Institutes of Health to P.B.

\section{References}

Acres, R.B., P.J. Conlon, D.Y. Mochizuki, and B. Gallis. 1986. Rapid phosphorylation and modulation of the $\mathrm{T} 4$ antigen on cloned helper T-cells induced by phorbol myristate acetate or antigen. J. Biol. Chem. 261: 16210-16214.

Bedinger. P., A. Moriarty, R.C. von Borstel II, N. J. Donovan, K.S. Steimer, and D.R. Littman. 1988. Internalization of the human immunodeficiency virus does not require the cytoplasmic domain of CD4. Nature 334: 162-165.

Campbell, D.G., J. Gagnon, K.B.M. Reid, and A.F. Williams. 1981. Rat brain Thy-1 glycoprotein. Biochem. J. 195: 15-30.

Chang, H.-C., T. Seki, T. Moriuchi, and J. Silver. 1985. Isolation and characterization of mouse Thy-1 genomic clones. Proc. Natl. Acad. Sci. 82: 3819-3823.

Chu, G., H. Hayakawa, and P. Berg. 1987. Electroporation for the efficient transfection of mammalian cells with DNA. Nucleic Acids Res. 15: 1311-1326.

Cohen, F., J. Novotny, M. Steinberg, D. Campbell, and A. Williams. 1981. Analysis of structural similarities between brain Thy-1 antigen and immunoglobulin domains. Biochem. J. 195: 31-40.

Dalchau, R. and J.W. Fabre. 1979. Identification and unusual tissue distribution of the canine and human homologues of Thy-1. I. Exp. Med. 149: 576-591. 
Dalgleish, A.G., P.C.L. Beverly, P.R. Clapham, D.H. Crawford, M.F. Greaves, and R.A. Weiss. 1984. The CD4 (T4) antigen is an essential component of the receptor for the AIDS retrovirus. Nature 312: 763-766.

Doetschman, T., N. Maeda, and O. Smithies. 1988. Targeted mutation of the Hprt gene in mouse embryonic stem cells. Proc. Nat1. Acad. Sci. 85: 8583-8587.

Dorin, J.R., J.D. Inglis, and D.J. Porteous. 1989. Selection for precise chromosomal targeting of a dominant marker by homologous recombination. Science 243: 1357-1360.

Ellis, J. and A. Bernstein. 1989. Gene targeting with retroviral vectors: Recombination by gene conversion into regions of nonhomology. Mol. Cell. Biol. 9: 1621-1627.

Evans, G.A., H.A. Ingraham, K. Lewis, K. Cunningham, T. Seki, T. Moriuchi, H.C. Chang, J. Silver, and R. Hyman. 1984. Expression of the Thy-1 glycoprotein gene by DNA-mediated gene transfer. Proc. Nat1. Acad. Sci. 81: 5532-5536.

Feinberg, A.P. and B. Vogelstein. 1983. A technique for radiolabeling DNA restriction endonuclease fragments to high specific activity. Anal. Biochem. 132: 6-13.

Gorman, C., R. Padmanabhan, and B.H. Howard. 1983. High efficiency DNA-mediated transformation of primate cells. Science 221: 551-553.

Gossler, A., A.L. Joyner, J. Rossant, and W.C. Skarnes. 1989. Mouse embryonic stem cells and reporter constructs to detect developmentally regulated genes. Science 244: 463465.

Hoxie, J.A., D.M. Matthews, K.J. Callahan, D.L. Cassel, and R.A. Cooper. 1986. Transient modulation and internalization of T4 antigen induced by phorbol esters. I. Immunol. 137: 1194-1201.

Ingraham, H.A. and G.A. Evans. 1986. Characterization of two atypical promoters and alternate mRNA processing in the mouse Thy-1.2 glycoprotein gene. Mol. Cell. Biol. 6: 29232931.

Jasin, M. and P. Berg. 1988. Homologous integration in mammalian cells without target gene selection. Genes Dev. 2: $1353-1363$.

Joyner, A.L., W.C. Skarnes, and J. Rossant. 1989. Production of a mutation in mouse En-2 gene by homologous recombination in embryonic stem cells. Nature 338: 153-156.

Kerr, W.G., G.P. Nolan, and L.A. Herzenberg. 1989. In situ detection of transcriptionally active chromatin and genetic regulatory elements in individual viable mammalian cells. Immunology, suppl. 2: 74-78.

Kim, H.-S. and O. Smithies. 1988. Recombinant fragment assay for gene targetting based on the polymerase chain reaction. Nucleic Acids Res. 16: 8887-8903.

Klatzman, D., E. Champagne, S. Chamaret, J. Gruest, D. Guetard, T. Hercend, J.-C. Gluckman, and L. Montagnier. 1984. T-lymphocyte T4 molecule behaves as the receptor for human retrovirus LAV. Nature 312: 767-768.

Landau, N.R., M. Warton, and D.R. Littman. 1988. The envelope glycoprotein of the human immunodeficiency virus binds to the immunoglobulin-like domain of CD4. Nature 334: 159-162.

Low, M.G. and P.W. Kincade. 1985. Phosphatidylinositol is the membrane-anchoring domain of the Thy-1 glycoprotein. Nature 318: 62-64.

Maddon, P.J., D.R. Littman, M. Godfrey, D.E. Maddon, L. Chess, and R. Axel. 1985. The isolation and nucleotide sequence of a cDNA encoding the T-cell-surface protein T4: A new member of the immunoglobulin gene family. Cell 42: 93-104.

Maddon, P.J., S.M. Molineaux, D.E. Maddon, K.A. Zimmerman, M.Godfrey, F.W. Alt, L. Chess, and R. Axel. 1987. Structure and expression of the human and mouse T4 genes. Proc. Natl. Acad. Sci. 84: 9155-9159.

Maniatis, T., E.F. Fritsch, and J. Sambrook. 1982. Molecular cloning: A laboratory manual. Cold Spring Harbor Laboratory, Cold Spring Harbor, New York.

Mansour, S.L., K.R. Thomas, and M.R. Capecchi. 1988. Disruption of the proto-oncogene int-2 in mouse embryo-derived stem cells: A general strategy for targeting mutations to non-selectable genes. Nature 336: 348-352.

Marsh, J. L., J. Erfle, and E.J. Wykes. 1984. The pIC plasmid and phage vectors with versatile cloning sites for recombinant selection by insertional inactivation. Gene 32: 481-485.

Moore, W. and R. Kautz. 1986. Data analysis in flow cytometry. In The handbook of experimental immunology led. D.M. Weir, L.A. Herzenberg, C.C. Blackwell, and L.A. Herzenberg), 4th ed. pp. 30.1-30.11. Blackwell, Edinburgh.

Mulligan, R.C. and P. Berg. 1980. Expression of a bacterial gene in mammalian cells. Science 209: 1422-1427.

Nolan, G.P., S. Fiering, J.-F. Nicolas, and L.A. Herzenberg. 1988. Fluorescence-activated cell analysis and sorting of viable mammalian cells based on $\beta$-D-galactosidase activity after transduction of Escherichia coli lacZ. Proc. Natl. Acad. Sci. 85: $2603-2607$.

Parks, D.R., L.L. Lanier, and L. A. Herzenberg. 1986. Flow cytometry and fluorescence activated cell sorting (FACS). In The handbook of experimental immunology (ed. D.M. Weir, L.A. Herzenberg, C.C. Blackwell, and L.A. Herzenberg), 4th ed. pp. 29.1-29.21. Blackwell, Edinburgh.

Peterson, A. and B. Seed. 1988. Genetic analysis of monoclonal antibody and HIV binding sites on the human lymphocyte antigen CD4. Cell 54: 65-72.

Rogozinski, L., A. Bass, E. Glickman, M.A. Talle, G. Goldstein, J. Wang, L. Chess, and Y. Thomas. 1984. The T4 surface antigen is involved in the induction of helper function. J. Immunol. 132: 735-739.

Sedivy, J.M., and P.A. Sharp. 1989. Positive genetic selection for gene disruption in mammalian cells by homologous recombination. Proc. Natl. Acad. Sci. 86: 227-231.

Southern, E. M. 1975. Detection of specific sequences among DNA fragments separated by gel electrophoresis. I. Mol. Biol. 98: 503-512.

Thompson, S., A.R. Clarke, A.M. Pow, M.L. Hooper, and D.W. Melton. 1989. Germ line transmission and expression of a corrected HPRT gene produced by gene targeting in embryonic stem cells. Cell 56: 313-321.

Tse, A.G.D., A.N. Barclay, A. Watts, and A.F. Williams. 1985. A glycophospholipid tail at the carboxyl terminus of the Thy-1 glycoprotein of neurons and thymocytes. Science 230: $1003-1008$.

Wilde, D.R., P. Marrack, J. Kappler, D.P. Dialynas, and F.W. Fitch. 1983. Evidence implicating L3T4 in class II MHC antigen reactivity. J. Immunol. 131: 2178-2183.

Williams, A. and J. Gagnon. 1982. Neuronal cell Thy-1 glycoprotein: Homology with immunoglobulin. Science. 216: 696-703.

Zimmer, A. and P. Gruss. 1989. Production of chimaeric mice containing embryonic stem (ES) cells carrying a homoeobox $\mathrm{Hox} 1.1$ allele mutated by homologous recombination. $\mathrm{Na}$ ture 338: $150-153$. 


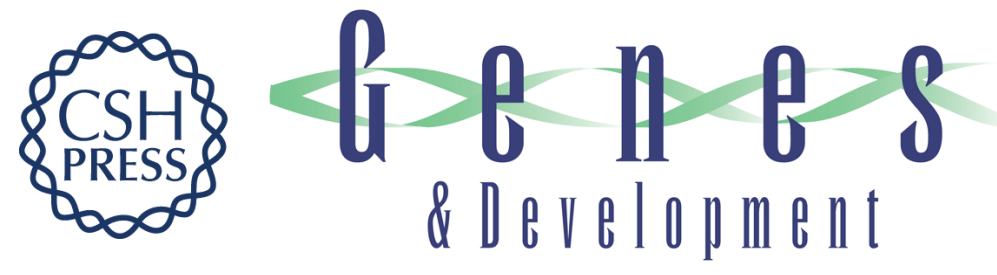

\section{Gene targeting at the human CD4 locus by epitope addition.}

M Jasin, S J Elledge, R W Davis, et al.

Genes Dev. 1990, 4:

Access the most recent version at doi:10.1101/gad.4.2.157

References This article cites 39 articles, 22 of which can be accessed free at: http://genesdev.cshlp.org/content/4/2/157.full.html\#ref-list-1

License

Email Alerting Service

Receive free email alerts when new articles cite this article - sign up in the box at the top right corner of the article or click here.

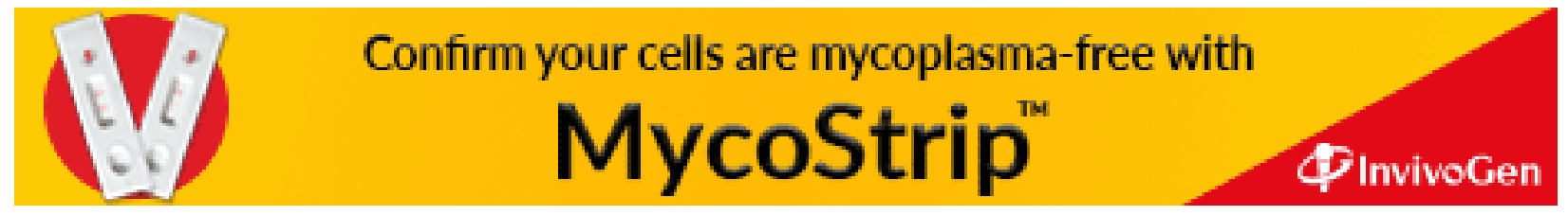

